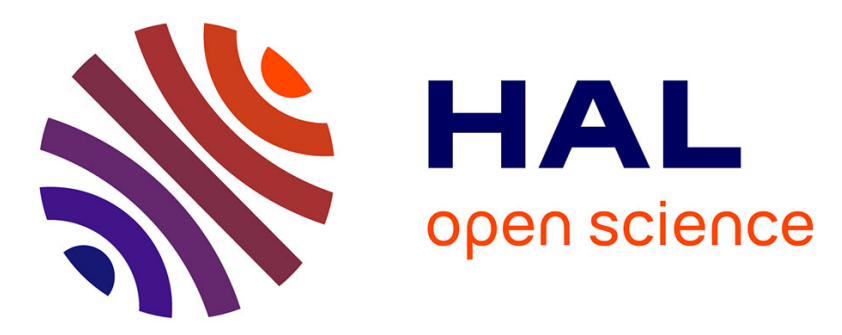

\title{
A Reduced Model of Three Ways Catalyst Converter and Stored Oxygen Rate Estimation Using Switched Observer
}

Caroline Ngo, Damien Koenig, Olivier Sename, Hubert Béchart

\section{- To cite this version:}

Caroline Ngo, Damien Koenig, Olivier Sename, Hubert Béchart. A Reduced Model of Three Ways Catalyst Converter and Stored Oxygen Rate Estimation Using Switched Observer. ECC 2013 - 12th biannual European Control Conference, Jul 2013, Zurich, Switzerland. pp.n/c. hal-00937438

\section{HAL Id: hal-00937438 \\ https://hal.science/hal-00937438}

Submitted on 28 Jan 2014

HAL is a multi-disciplinary open access archive for the deposit and dissemination of scientific research documents, whether they are published or not. The documents may come from teaching and research institutions in France or abroad, or from public or private research centers.
L'archive ouverte pluridisciplinaire HAL, est destinée au dépôt et à la diffusion de documents scientifiques de niveau recherche, publiés ou non, émanant des établissements d'enseignement et de recherche français ou étrangers, des laboratoires publics ou privés. 


\title{
A Reduced Model of Three Ways Catalyst Converter and Stored Oxygen Rate Estimation Using Switched Observer
}

\author{
Caroline Ngo, Damien Koenig, Olivier Sename and Hubert Béchart
}

\begin{abstract}
Pollutant emissions limitations ruled by the latest standards force car manufacturers to improve after treatment systems. This improvement is achieved by new systems on one hand, and by more efficient control strategies, on the other. This paper describes a 0-D model of Three Ways Catalyst converter (TWC) which is able to reproduce the transient dynamics of the converter although simple. A switched observer of stored oxygen rate is derived from this reduced model, and its convergence is proved. An estimation of the oxygen capacity of TWC provides precious information for on-board diagnosis or monitoring purpose.

First, a description of the TWC dynamics and its reduced model will be described, then a discrete time switched observer of the stored oxygen rate and the free site capacity estimation by least squares method are presented.
\end{abstract}

\section{INTRODUCTION}

Incomplete fuel combustion in cylinder leads to pollutants emissions. Nowadays, severe norms impose car manufacturers strict pollutant emissions regulations. As a result, exhaust gas after treatment systems need to become more efficient. Manufacturers meet the constraints by developing new technologies, but also through more sophisticated engine control strategies. The present study deals with the major after treatment system of Spark Ignition (SI) engine : the Three Ways Catalyst (TWC) converter.

The distinctive feature of Three Ways Catalyst is its ability to convert the three major regulated pollutants $(\mathrm{CO}, \mathrm{HC}$ and $N O_{x}$ ). Pollutants optimum conversion require the fuel air ratio to be at stoichiometry value. Above this value, mixture is defined as rich (excess of fuel in mixture) whereas below, the mixture is defined as lean (excess of oxygen). The fuel air ratio, through the injected fuel quantity in the engine, is controlled by Exhaust Gas Oxygen (EGO) sensor which indicates the presence of oxygen in exhaust pipe. However, catalyst system control strategy based on exhaust fuel air ratio measurements, without taking account of its internal dynamics, is not enough to meet futures restrictions. Over the years, researches focused on TWC converter mathematical models. However, modeling this system is a complex task due to the numerous chemical reactions involved, as presented in [15] [16].

Caroline Ngo and Hubert Béchart are with Renault, 1 Avenue du Golf, TCR LAB 0 12, 78288 Guyancourt Cedex, France (caroline.ngo, hubert.bechart) @renault.com

Damien Koenig and Olivier Sename are with GIPSA-Lab, Grenoble INP - Université Joseph Fourier, 11 rue des Mathématiques, BP46, 38402 SAINT MARTIN D'HERES Cedex, France (damien.koenig, olivier.sename) dgipsa-lab.grenoble-inp.fr
Many reduced models of TWC converter have been developed to satisfy new engine management strategy ([3][4][5][11][17]). Reduced model from [5] is focused on the oxygen storage and release rates, described by a static function. Transport time delay was assumed to be negligible. This model is very simple, however, dynamic response to TWC transients is not taken into account.

As in [5], authors in [11] described a simplified model dominated by the oxygen storage and release dynamics modeled by a polynomial function which parameters are identified from experimental data obtained at different engine conditions. The presented model include the effects of space velocity. These models are focused on the main dynamic of TWC : the oxygen storage dynamics. They are simple but have many parameters to adjust.

This paper aims to respond to model based needs to meet future standards and present an application of switched observer to chemical process.

A 0-D physical model based on simplified dynamics of TWC from [1] is presented, also focused on oxygen storage dynamics. This model has been validated on experimental results. A switched linear observer has been designed for oxygen storage rate monitoring, designed by solving multiple Linear Matrix Inequality (LMI) and the obtained gains guarantee the stability whatever switching sequence. Estimation of oxygen free sites density is done using least squares algorithm to take into account this parameter deviation in observer. An application will illustrate the presented method.

Notations : $(.)^{T}$ stands for transpose matrix and $()>$. denotes a positive definite matrix.

\section{Main Dynamics of Three Ways CATAlyst CONVERTER}

\section{A. TWC dynamics focused on oxygen storage}

Exhaust gas of a SI engine is mainly composed of unburnt hydrocarbons $(H C)$, carbon monoxides $(C O)$, nitrogen oxides $\left(N O_{x}\right)$, which are the major regulated pollutants, and oxygen $\left(\mathrm{O}_{2}\right)$, essential to convert pollutants. The TWC is able to convert these three pollutants when gas flows through it. Indeed, thanks to its internal structure covered by precious metal (Palladium, Platinum, Rhodium), the TWC promote $H C / C O$ oxidation and $N O_{x}$ reduction reactions and convert them into water, carbon oxide and nitrogen.

$N O_{x}$ reduction or $\mathrm{HC} / \mathrm{CO}$ oxidation are realized according to the exhaust gas composition characterized by the Fuel Air Ratio, denoted R. When the gas is rich $(R>1), N O_{x}$ 
are eliminated by $H C$ and $C O$ present in excess, whereas, during lean phase $(R<1), H C$ and $C O$ are converted by $N O_{x}$ present in excess this time. As illustrated by TWC efficiency curves (Fig. 1), best conversion rate for both reduction and oxidation reactions is located at stoichiometry value $(R=1)$.

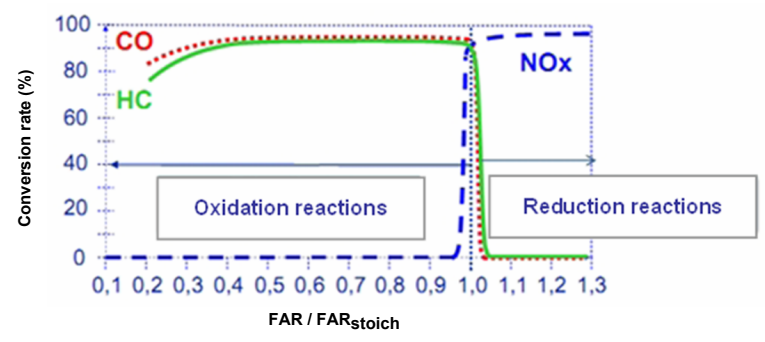

Fig. 1. Conversion efficiency

However, keeping $\mathrm{R}$ at stoichiometry value is impossible due to the high transients in driving conditions. To increase the efficiency of TWC conversions, Ceria oxides $\left(\mathrm{Ce}_{2} \mathrm{O}_{3}\right)$ are added to fix oxygen. During lean phase, $\mathrm{O}_{2}$ and $N O_{x}$ excess facilitate Ceria oxidation, once stored, they can be released to convert pollutants when mixture is rich. By varying the fuel air ratio around stoichiometry, oxygen storage and release are stimulated and pollutants conversion is possible for any air-fuel mixture if storage management is optimum. Efficiency is then between $90 \%$ and $100 \%$, and also depends on TWC temperature and gas flow rate. Indeed, heat activate the catalyst (chemical kinetics) and flow rate, if too high, prevent gas to stay long enough for being convert (mixture transport along converter).

TWC is affected by sulfur dioxides poisoning, but also by heat damages (overheat during misfires) which decrease the efficiency of conversions in time. As a result, the density of free sites for oxygen storage decrease, less oxygen is stored and pollutants at exhaust increase. Ageing of TWC represented by density of free sites has to be taken into account in the model and estimated.

\section{B. Chemical reactions}

As described in the previous section, five reactions mainly describe TWC dynamics. Exhaust gas elements react with each other according those main chemical reactions :

- $N O_{x}$ reduction : $\frac{1}{x} N O_{x}+C O \rightarrow C O_{2}+\frac{1}{2 x} N_{2}$

- $\mathrm{HC}$ oxidation : $\mathrm{HC}+\frac{1}{2} \mathrm{O}_{2} \rightarrow \frac{1}{2} \mathrm{H}_{2} \mathrm{O}+\mathrm{CO}_{2}$

- $\mathrm{CO}$ oxidation : $\mathrm{CO}+\frac{1}{2} \mathrm{O}_{2} \rightarrow \mathrm{CO}_{2}$

The oxygen storage dynamics is modeled by the following reactions :

- Oxide adsorption when $R<1$ : $\frac{1}{2} \mathrm{O}_{2}+\mathrm{Ce}_{2} \mathrm{O}_{3} \rightarrow 2 \mathrm{CeO}_{2}$

- Oxide desorption and CO conversion when $R \geq 1$ : $\mathrm{CO}+2 \mathrm{CeO}_{2} \rightarrow \mathrm{CO}_{2}+\mathrm{Ce}_{2} \mathrm{O}_{3}$

\section{Reduced model of Three Ways Catalyst}

Previous reactions can be grouped to reduce the model : one involve reducers and the other, involve oxides.
$\mathrm{HC} / \mathrm{CO} / \mathrm{H}_{2}$ can be represented by an equivalent reducer, denoted RED, and $\mathrm{O}_{2} / \mathrm{NO}_{x}$ by equivalent oxide, denoted OX. Indeed, in first approximation, $\mathrm{CO}$ and $\mathrm{H}_{2}$ have similar behavior and quantities of $H C$ and $N O_{x}$ are negligible compare to other components of exhaust gas. The previous chemical equations become :

- Oxygen adsorption : $O X+2 \Sigma \rightarrow 2 \Sigma^{*}$

- Pollutants reduction : $\Sigma^{*}+\mathrm{RED} \rightarrow \mathrm{\Sigma}+\mathrm{CO}_{2} / \mathrm{H}_{2} \mathrm{O}$

With :

$\Sigma / \Sigma^{*}$ : Free/occupied oxygen storage site

OX : Equivalent oxide

RED : Equivalent reducer

The exhaust fuel air ratio is expressed with concentrations of equivalent reducer and oxide by :

$$
R_{\text {out }}=1+K\left(\frac{1}{2} C_{R E D}^{\text {out }}-C_{O X}^{\text {out }}\right)
$$

All these simplifications lead to the following reaction rate equations :

- Oxygen rate dynamic :

$$
\dot{\theta}=2 k_{a d s} C_{O X}^{\text {out }}(1-\theta)-k_{\text {red }} C_{R E D}^{\text {out }} \theta
$$

- Exhaust fuel air ratio dynamic :

$$
\begin{aligned}
\dot{R}_{\text {out }} & =\operatorname{vvh}\left(R_{\text {in }}-R_{\text {out }}\right) \\
& +\frac{K \rho}{2}\left(2 k_{\text {ads }} C_{O X}^{\text {out }}(1-\theta)-k_{\text {red }} C_{R E D}^{\text {out }} \theta\right)
\end{aligned}
$$

With :

$\theta$ : Oxygen ratio stored in TWC

$R_{\text {in }}, R_{\text {out }}$ : Inlet, resp. outlet fuel air ratio

$v v h$ : Exhaust mass flow rate

$T$ : Gas temperature in TWC

$K$ : Concentration-FAR conversion coefficient

$\rho$ : Density of free sites for oxygen storage

$k_{a d s}:$ Adsorption kinetic $\left(k_{a d s}=k_{a d s 0} e^{\frac{-E_{a d s}}{r T}}\right)$

$k_{\text {red }}$ : Reduction kinetic $\left(k_{r e d}=k_{\text {red }} e^{\frac{-E_{r e d}}{r T}}\right)$

$r$ : Gas constant

$E_{a d s}, E_{\text {red }}$ : Adsorption, resp. desorption activation energy

$C_{O X}^{o u t}, C_{R E D}^{o u t}:$ Oxide, resp. reducer concentration

And parameters $k_{a d s 0}, k_{r e d 0}, E_{a d s}, E_{\text {red }}$ are constant.

Other assumptions can be considered : when mixture is rich, it can be supposed that few oxides are present and adsorption is negligible, so $k_{a d s}=0$; on the contrary, when mixture is lean, $k_{\text {red }}=0$ since reduction reactions are negligible.

Expressions of oxide and reducer concentration from (1) can be reduced again and approximated by :

$$
\begin{gathered}
C_{O X}^{\text {out }}=\frac{1-R_{\text {out }}}{K}, \text { if } R_{\text {out }}<1,0 \text { otherwise } \\
C_{R E D}^{\text {out }}=\frac{2\left(R_{\text {out }}-1\right)}{K}, \text { if } R_{\text {out }} \geq 1,0 \text { otherwise }
\end{gathered}
$$


The model is composed of 3 inputs $\left(u=\left[R_{i n}, v v h, T\right]\right)$, 2 states $\left(x=\left[\theta, R_{\text {out }}\right]\right)$ and measured output $\left(y=R_{\text {out }}\right)$.

The non linear system is given by :

$$
\begin{gathered}
R_{\text {out }}<1 \quad\left\{\begin{array}{c}
\dot{x}_{1}=\frac{2}{K} k_{\text {ads }}\left(u_{3}\right)\left(1-x_{1}\right)\left(1-x_{2}\right) \\
\dot{x}_{2}=u_{2}\left(u_{1}-x_{2}\right) \\
+k_{\text {ads }}\left(u_{3}\right) \rho\left(1-x_{1}\right)\left(1-x_{2}\right)
\end{array}\right. \\
R_{\text {out }} \geq 1 \quad\left\{\begin{array}{c}
\dot{x_{1}}=\frac{2}{K} k_{\text {red }}\left(u_{3}\right) x_{1}\left(1-x_{2}\right) \\
\dot{x_{2}}=u_{2}\left(u_{1}-x_{2}\right) \\
+k_{\text {red }}\left(u_{3}\right) \rho x_{1}\left(1-x_{2}\right)
\end{array}\right.
\end{gathered}
$$

Simulation of the non linear model results against experimental data is presented in the following figures :

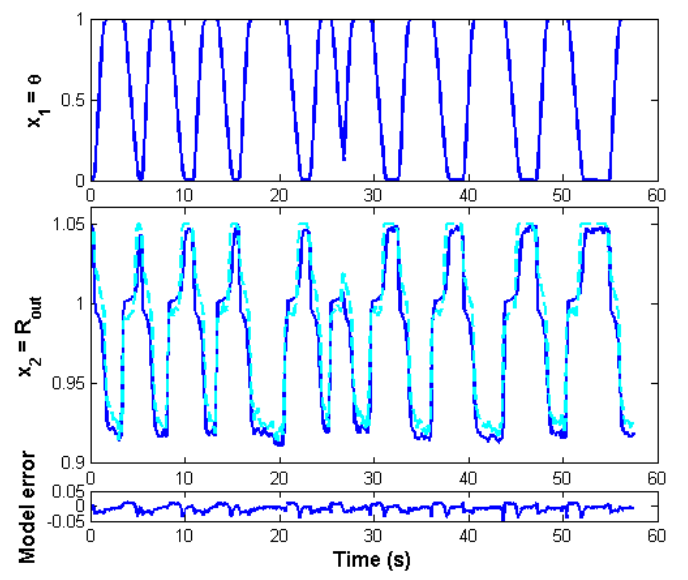

Fig. 2. Oxygen rate model and Fuel air ratio from experimental measurements (dashed) compared to the non linear model (solid)

Results of the non linear model simulation shows good fit of the model to data (Fig.2). The reduced model behave as expected : during rich phase, all stored oxygen have been released and $\theta=0$, whereas during lean phase, $\theta=1$ meaning that all free oxygen sites are occupied. The oxygen storage and release dynamics (TWC breathing) are also well modeled : during rich to lean and lean to rich transitions, $R_{\text {out }}=1$. In the first case, TWC store all the oxygen present in gas and since mixture is lean, no oxide and reducer are present are TWC exhaust, so $R_{\text {out }}=1$ during storage. In the second case, stored oxygen is released and react with reducer, as a result $R_{\text {out }}=1$ during this process.

In order to apply a switched observer, this reduced model is linearized.

\section{SWITCHED LINEAR MODEL}

The choice of switched system obtained by linearization over other form of representation is due to the nature of TWC's operating range (rich or lean ranges). In addition, the model is clearly non linear but dynamics are simple.

Let consider the following switched system :

$$
\left\{\begin{array}{l}
\dot{x}(t)=\sum_{i=1}^{n} \mu_{i}\left(x_{2}(t)\right)\left(A_{i} x(t)+B_{i} u(t)+d_{i}\right) \\
y(t)=C x(t)
\end{array}\right.
$$

With : $A_{i}=\left.\frac{\partial f(x, u)}{\partial x}\right|_{x_{i}, u_{i}}, B_{i}=\left.\frac{\partial f(x, u)}{\partial u}\right|_{x_{i}, u_{i}}, C_{i}=C=$ [0 1$], d_{i}=f\left(x_{i}, u_{i}\right)-A_{i} x_{i}-B_{i} u_{i}$ And : $\dot{x}(t)=f(x(t), u(t))$

The linearized system is given by the following matrices $\left(A_{i}, B_{i}, d_{i}\right)$ :

- If $R_{\text {out }}<1$ :

$$
\begin{aligned}
& A_{i}= \\
& \left(\begin{array}{cc}
\frac{2}{K} k_{a d s i}\left(x_{2 i}-1\right) & \frac{2}{K} k_{a d s i}\left(x_{1 i}-1\right) \\
\rho k_{a d s i}\left(x_{2 i}-1\right) & -u_{2 i}+\rho k_{a d s i}\left(x_{1 i}-1\right)
\end{array}\right) \\
& B_{i}= \\
& \left(\begin{array}{ccc}
0 & 0 & \frac{2}{K} \frac{E_{a d s}}{r u_{3 i}^{2}} k_{a d s i}\left(x_{1 i}-1\right)\left(x_{2 i}-1\right) \\
u_{2 i} & u_{1 i}-x_{2 i} & \frac{E_{a d s}}{r u_{3 i}^{2}} \rho k_{a d s i}\left(x_{1 i}-1\right)\left(x_{2 i}-1\right)
\end{array}\right) \\
& d_{i}=f\left(x_{i}, u_{i}\right)-A_{i}\left(\begin{array}{c}
x_{1 i} \\
x_{2 i}
\end{array}\right)-B_{i}\left(\begin{array}{c}
u_{1 i} \\
u_{2 i} \\
u_{3 i}
\end{array}\right)
\end{aligned}
$$

- If $R_{\text {out }} \geq 1$ :

$$
\begin{aligned}
& A_{i}= \\
& \left(\begin{array}{cc}
\frac{2}{K} k_{r e d i}\left(1-x_{2 i}\right) & -\frac{2}{K} k_{r e d i} x_{1 i} \\
\rho k_{r e d i}\left(1-x_{2 i}\right) & -u_{2 i}-\rho k_{r e d i} x_{1 i}
\end{array}\right) \\
& B_{i}= \\
& \left(\begin{array}{ccc}
0 & 0 & \frac{2}{K} \frac{E_{r e d}}{r u_{3 i}^{2}} k_{r e d i} x_{1 i}\left(1-x_{2 i}\right) \\
u_{2 i} & u_{1 i}-x_{2 i} & \frac{E_{r e d}}{r u_{3 i}^{2}} \rho k_{r e d i} x_{1 i}\left(1-x_{2 i}\right)
\end{array}\right) \\
& d_{i}=f\left(x_{i}, u_{i}\right)-A_{i}\left(\begin{array}{c}
x_{1 i} \\
x_{2 i}
\end{array}\right)-B_{i}\left(\begin{array}{c}
u_{1 i} \\
u_{2 i} \\
u_{3 i}
\end{array}\right)
\end{aligned}
$$

Each model i represents an operating point and to switch between the $n$ models, measured $x_{2}=y=R_{\text {out }}$ is chosen as switching variable. $\mu_{i}$ is the switching signal and satisfies the following convex properties :

$$
\left\{\begin{array}{l}
\sum_{i=1}^{n} \mu_{i}(x(t))=1 \\
0 \leq \mu_{i}(x(t)) \leq 1
\end{array}\right.
$$

Here, $\mu_{i}$ is constant and equals to 0 or 1 according to switching variable value so, if $\mu_{i}\left(x_{2}(t)\right)=1,\left(A_{i}, B_{i}, d_{i}\right)$ are activated.

Four set of points are chosen to model the dynamics $(n=4)$, they represent lean and rich steady state phases and fuel air ratio transitions. Operating points are obtained by mathematical identification based on non linear model data.

The chosen points are given in the following table :

\begin{tabular}{|l|c|c|c|c|c|c|}
\cline { 3 - 7 } \multicolumn{2}{c|}{} & $\mathbf{x}_{\mathbf{1 i}}$ & $\mathbf{x}_{\mathbf{2}}$ & $\mathbf{u}_{\mathbf{1}}$ & $\mathbf{u}_{\mathbf{2}}$ & $\mathbf{u}_{\mathbf{3 i}}$ \\
\hline \multirow{2}{*}{ Rout $<\mathbf{1}$} & $\mathbf{i}=\mathbf{1}$ & 0.973 & 0.956 & 0.952 & 12.51 & 473 \\
\cline { 2 - 7 } & $\mathbf{i}=\mathbf{2}$ & 0.989 & 0.998 & 0.999 & 11.61 & 400 \\
\hline \multirow{2}{*}{ Rout $\geq \mathbf{1}$} & $\mathbf{i}=\mathbf{3}$ & 0.447 & 1.004 & 1.003 & 14.12 & 596 \\
\cline { 2 - 7 } & $\mathbf{i}=\mathbf{4}$ & 0.024 & 1.038 & 1.041 & 11.05 & 569 \\
\hline
\end{tabular}

TABLE I

SETS OF OPERATING POINTS FOR THE FOUR SUB MODELS 
In the case where switching variable is not measurable, this switched linear model can be extended to estimate the switching variable. This approach is presented in [10],[9].

Validation is done from non linear model data obtained by simulation with experimental data in input. Inlet FAR is a step signal between the values of $R_{\text {in }}=0.92$ and $R_{\text {in }}=$ 1.05 with non constant sample time, temperature and mass flow rate are constant. Model identification results are shown in the following figures :

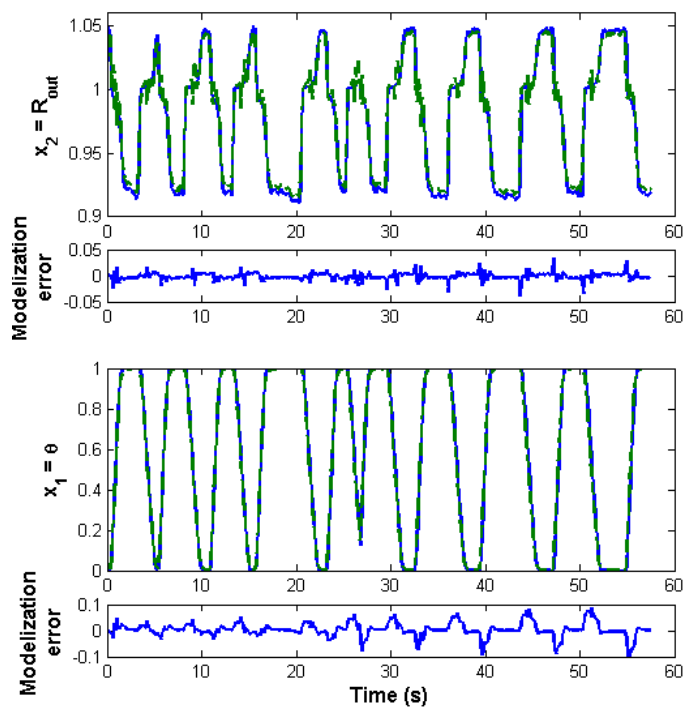

Fig. 3. Fuel air ratio and Oxygen fraction rate from non linear model (solid) compared to the switched model (dashed)

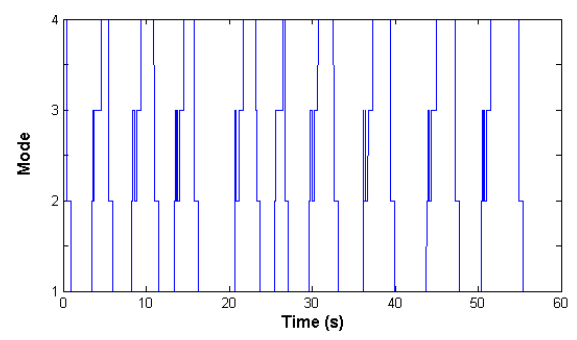

Fig. 4. Switching sequence

Good results are obtained by this switched model although simple : modelization error of FAR remains small in spite of noise from switches. Whereas, model of oxygen rate from switched model is equivalent to the one from non linear model, and is not affected by switching sequence. Noise from switches of FAR is not a problem since this value is measurable. This model has been applied on data different from the one used in identification process which justify the validity of this switched model.

In the following sections, a discrete time switched observer and a parameter estimation are presented for $x_{1}=\theta$ and $\rho$ monitoring. Parameter estimation is used as an input for the observer in order to take into account the TWC ageing.

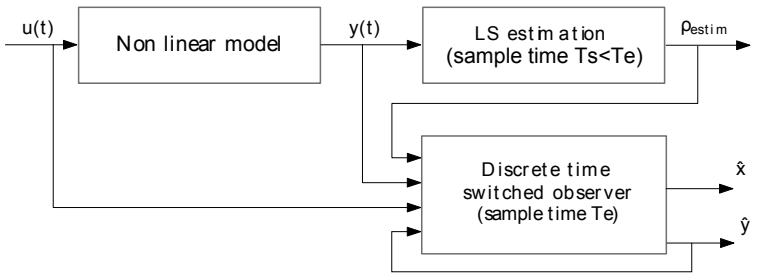

Fig. 5. Observation and estimation process scheme

\section{DISCRETE TIME SWITCHED OBSERVER : APPLICATION TO OXYGEN STORAGE RATE $\theta$}

Optimization of the oxygen storage management can be achieved by monitoring the stored oxygen fraction $\theta$. Since this value is not measurable, an observer has to be designed. This section presents a discrete time switched observer with multiple Lyapunov functions designed by solving LMIs ([2][12]).

\section{A. Switched observer synthesis}

The expression of the discrete time switched observer is of the following form :

$\left\{\begin{array}{l}\hat{x}_{k+1}=\sum_{i=1}^{n=4} \mu_{i}\left(x_{2 k}\right)\left(A_{d i} \hat{x}_{k}+B_{d i} u_{k}+d_{d i}+L_{i}\left(y_{k}-\hat{y}_{k}\right)\right) \\ \hat{y}_{k}=C_{d} \hat{x}_{k}\end{array}\right.$

Where $L_{i}$ is the observer gain of the current model $\mathrm{i}$ and $A_{d i}, B_{d i}, d_{d i}$ and $C_{d}$ are the discrete matrix of $A_{i}, B_{i}, d_{i}$ and $C$, respectively (with a sample time of $10 \mathrm{~ms}$ ).

These matrices depend on the known parameter $\rho$ estimated by least squares algorithm described in Section V.

From (3) and (4), the state estimation error dynamic is given by :

$$
\begin{gathered}
e_{k+1}=\sum_{i=1}^{n=4} \mu_{i}\left(x_{2 k}\right)\left(A_{i}-L_{i} C\right) e_{k} \\
e_{k}=x_{k}-\hat{x}_{k}
\end{gathered}
$$

Problem : Considering the switched model (3) and the switched observer (4), find the gains $L_{i}$ such that the estimation error dynamics (5) is globally asymptotically stable.

Theorem 1 : Observer gain For $i, j \in 1,2, \ldots, n$, where i represent $\mathrm{k}$ and $\mathrm{j}, \mathrm{k}+1$, if the pair $\left(A_{d i}, C\right)$ is detectable for all $i$, if there exist matrices $P_{i} \in \mathbb{R}^{m \times m}$, positive definite and symmetric and, $U_{i} \in \mathbb{R}^{m \times p}$ such that the following LMI is verified for all $(i, j)$ :

$$
\left[\begin{array}{cc}
-P_{i} & A_{d i}^{T} P_{i}^{T}-C_{d}^{T} U_{i}^{T} \\
P_{i} A_{d i}-U_{i} C_{d} & P_{j}-2 P_{i}
\end{array}\right]<0
$$

then, the discrete time switched observer (4) of system (3) exist and the gains are given by $L_{i}=U_{i} P_{i}^{-1}$.

Sketch of proof : (steps similar to [7], [12]) 
To guarantee convergence toward 0 of the estimation error (5), the following inequality should be satisfied :

$$
V\left(k+1, e_{k+1}\right)-V\left(k, e_{k}\right)<0
$$

for all $\mathrm{k}$, where $V\left(k, e_{k}\right)=e_{k}^{T} P_{k} e_{k}>0$ is a candidate Lyapunov function, with $P_{k}=P_{k}^{T}$ and $P_{k}>0$.

Let $P_{i}=P_{k}$ and $P_{j}=P_{k+1}$, the difference $V(k+$ $\left.1, e_{k+1}\right)-V\left(k, e_{k}\right)$ along the solution of (5) becomes :

$-P_{i}+\left(A_{d i}^{T} P_{i}^{T}-C_{d}^{T} L_{i}^{T} P_{i}^{T}\right) P_{i}^{-1} P_{j} P_{i}^{-1}\left(P_{i} A_{d i}-P_{i} L_{i} C_{d}\right)<0$

By Schur's complement, this inequality is equivalent to :

$$
\left[\begin{array}{cc}
-P_{i} & \left(A_{d i}-L_{i} C_{d}\right)^{T} P_{i}^{T} \\
P_{i}\left(A_{d i}-L_{i} C_{d}\right) & -P_{i} P_{j}^{-1} P_{i}
\end{array}\right]<0
$$

With $U_{i}=P_{i} L_{i}$, and by noticing that $P_{i}^{T} P_{j}^{-1} P_{i} \geq 2 P_{i}-P_{j}$, the LMI to solve becomes :

$$
\left[\begin{array}{cc}
-P_{i} & A_{d i}^{T} P_{i}^{T}-C_{d}^{T} U_{i}^{T} \\
P_{i} A_{d i}-U_{i} C_{d} & P_{j}-2 P_{i}
\end{array}\right]<0
$$

\section{B. Switched observer synthesis with pole assignment}

A solution to improve the performances of the observer is to add constraints on matrices $A_{d i}$ and $C_{d}$ in the previous LMI to force poles assignment in sub-region ([12],[14]).

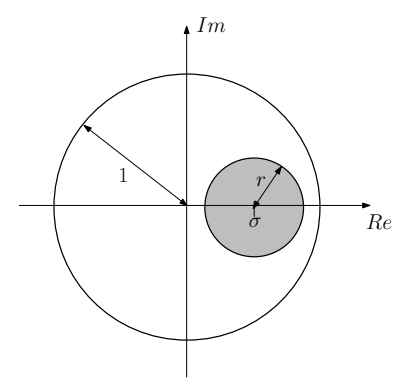

Fig. 6. Sub-region for pole location

Theorem 2 : Pole placement To place the poles of the observer into a circle smaller than the unit circle, a simple change of matrix in the previous LMI is used : $A_{d i}$ is replaced by $\frac{A_{d i}-\sigma I}{r}$ and $C_{d}$ is replaced by $\frac{C_{d}}{r}$, where $\sigma$ is the small circle center coordinates and $r$ is the small circle radius.

The LMI to solve becomes :

$$
\left[\begin{array}{cc}
-P_{i} & \left(\frac{A_{d i}-\sigma I}{r}\right)^{T} P_{i}^{T}-\left(\frac{C_{d}}{r}\right)^{T} U_{i}^{T} \\
P_{i}\left(\frac{A_{i d}-\sigma I}{r}\right)-U_{i}\left(\frac{C_{d}}{r}\right) & P_{j}-2 P_{i}
\end{array}\right]<0
$$

\section{Observer results}

The switched observer has been validated against the same data used previously in switched model validation paragraph. Initial states values are different from data to see observer performances. Pole placement application will not be illustrated.

Figures show that observer converge and is not affected by switches. Maximum value of error estimation for $\hat{x}_{1}$ and
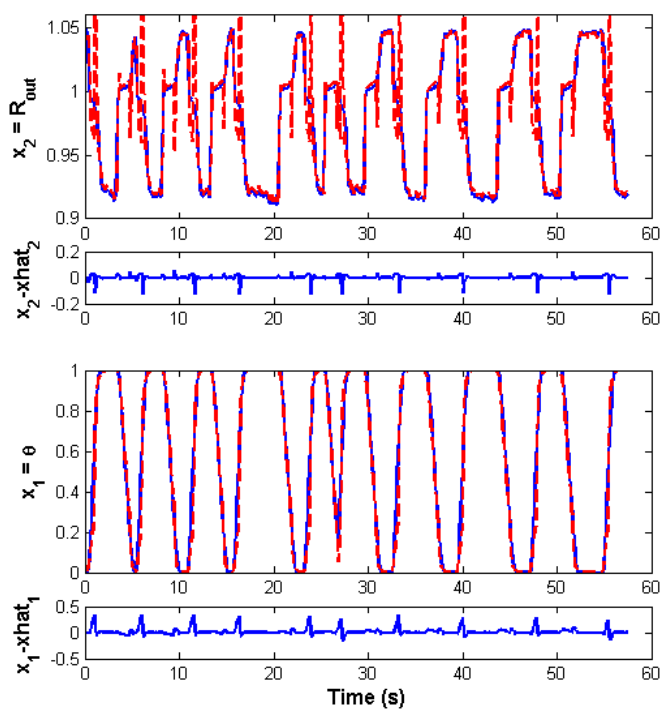

Fig. 7. Fuel air ratio and Oxygen fraction rate from non linear model (solid) compared to observer result (dashed)

$\hat{x}_{2}$ is $30 \%$. Although this value is quite high, error converge quickly to 0 such as the results are satisfactory.

The presented results prove that observer is efficient for oxygen storage rate monitoring (Fig.7) which can be employed in advance control strategies including oxygen storage management.

\section{FREE SITES DENSITY $\rho$ ESTIMATION BY LEAST SQUARES ALGORITHM}

Future standards will impose On Board Diagnosis (OBD) of TWC. Catalytic converters are mostly affected by sulfur poisoning or overheat which reduce the surface available to convert pollutants. As a result, density of free oxygen site $\rho$ decrease, leading to efficiency loss of TWC. By monitoring the parameter $\rho$, the TWC ageing can be taken into account by the observer to adapt oxygen storage management, and is a precious information for OBD.

To monitoring $\rho$, an estimation by least squares method is chosen (see [13]). One can remark that an adaptive observer, PI observer or addition of the parameter in the state vector could have been used to estimate both states and parameter as in [8] or [6].

However, two reasons explain this choice :

- The parameter $\rho$ varies slowly (years), so online estimation is not useful for observer.

- System with addition of $\rho$ as a state and $\rho(k+1)=\rho(k)$, is not observable when $x_{1 i}=\theta_{i}=(0,1)$ or $x_{2 i}=1$ (eq.(2)).

As a result, decoupling the problem of observation and estimation was preferable.

The recursive least squares estimation is done with the values from the non linear model. The non linear model presented in section II is of the form :

$$
h(x)=\rho f(x, u)+g(x, u)
$$


With :

$$
\begin{aligned}
& h(x)=\dot{x}_{2} \\
& g(x, u)=u_{2}\left(u_{1}-x_{2}\right) \\
& \begin{cases}f(x, u)=k_{\text {ads }}\left(u_{3}\right)\left(1-x_{1}\right)\left(1-x_{2}\right) & \left(\text { if } x_{2}<1\right) \\
f(x, u)=k_{\text {red }}\left(u_{3}\right) x_{1}\left(1-x_{2}\right) & \left(\text { if } x_{2} \geq 1\right)\end{cases}
\end{aligned}
$$

Since $\dot{x}_{2}$ is used to estimate the parameter, the least square algorithm is more advantageous : data from non linear model are stored to run the algorithm afterward. Moreover, the parameter $\rho$ varies slowly, the sample time of estimation process can be smaller than the observer one (see Fig. 5) to provide known parameter to observer as online estimator.

The objective is to estimate the parameter $\rho$ using least squares criteria :

$$
J_{\Theta}(N)=\sum_{i=0}^{N}\left(y(i)-\Theta^{T} \Phi(i-1)\right)^{2}
$$

With :

$y$ : Measured output

$\Phi$ : Vector composed of measured output and input

$\Theta$ : Vector of parameter to be estimated

Recursive least squares algorithm can be applied by writing :

$$
\begin{aligned}
& y(x, u)=h(x)-g(x, u) \\
& \Phi(x, u)=f(x, u) \\
& \Theta=\rho
\end{aligned}
$$

The following result is obtained by running estimation algorithm with a sample time of Ts $=1 \mathrm{e}-4 s$ with an observer running with a sample time of $\mathrm{Te}=0.06 s$.

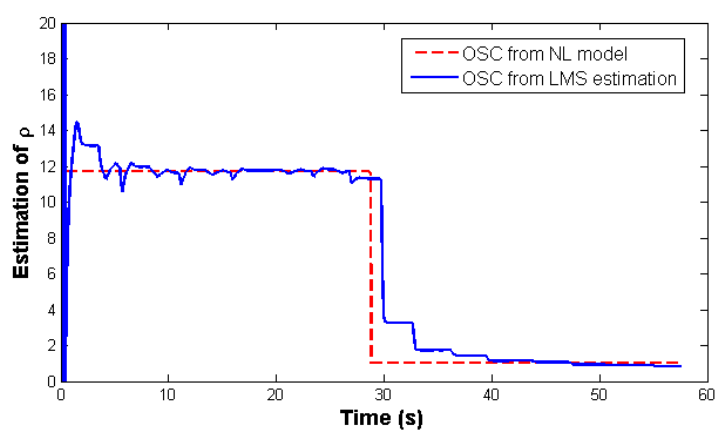

Fig. 8. Free site density estimation (solid) - Parameter value (dashed)

The estimation converge to the parameter value even when parameter real value changes, showing that this algorithm used in a recursive way is fast and suitable for monitoring application, especially the ageing of TWC.

\section{CONCLUSION}

In this paper, a reduced model well suited for control thanks to its simplicity in the form of ordinary differential equations of small order, is developed based on oxygen dynamics of the TWC.
A multiple model linearization representation permits to design a discrete switched observer by solving multiple LMIs, considering all the possible cases. Structural constraints can be added in observer synthesis to force its poles to be in a specified circle. A parameter estimation based on recursive least squares algorithm is provided, treated separately from the observer problem.

Successful application of the oxygen fraction rate $\theta$ observation and estimation of the free site density $\rho$ will improve the oxygen storage management, needed for future standards.

\section{REFERENCES}

[1] F. Aimard, S. Li, and M. Sorine. Mathematical modeling od automotive three way catalytic converters with oxygen storage capacity. In IFAC Workshop ICASAV'95. Toulouse, October 1995.

[2] A. Akhenak, M. Chadli, D. Maquin, and J. Ragot. State estimation of uncertain multiple model with unknown inputs. In 43rd IEEE Conference on Decision and Control, volume 4, pages 3563 - 3568, 2004.

[3] T. Auckenthaler, C. Onder, and H.Geering. Online estimation of the oxygen storage level of a three-way catalyst. SAE International, March 2004.

[4] Mario Balenovic, Jerome Edwards, and Ton Backx. Vehicle application of model-based catalyst control. Control Engineering Practice, 14(3) :223-233, March 2006.

[5] Erich P. Brandt, Yanying Wang, and Jessy W. Grizzle. Dynamic modeling of a three-way catalyst for si engine exhaust emission control. IEEE Transactions on Control Systems Technology, 8(5) :767776, September 2000.

[6] M. Chadli, A. Akhenak, J. Ragot, and D. Maquin. State and unknown input estimation for discrete time multiple model. Journal of the Franklin Institute, 346(6):593 - 610, 2009.

[7] J. Daafouz, P. Riedinger, and C. Iung. Stability analysis and control synthesis for switched systems : a switched lyapunov function approach. IEEE Transactions on Automatic Control, 47(11) :1883 1887, November 2002.

[8] A. Guyader and Q. Zhang. Adaptive observer for discrete time linear time varying systems. In 13th IFAC IFORS Symp. on Sys. Identification (SYSID). Rotterdam, 2003.

[9] D. Ichalal, B. Marx, D. Maquin, and J. Ragot. Observer design and fault tolerant control of takagi-sugeno nonlinear systems with unmeasurable premise variables. Fault Diagnosis in Robotic and Industrial Systems, 2012.

[10] D. Ichalal, B. Marx, J. Ragot, and D. Maquin. State estimation of takagi-sugeno systems with unmeasurable premise variables. IET Control Theory and Applications, 4 :897-908, 2010.

[11] James C. Peyton Jones, J. Brian Roberts, Pierre Bernard, and Richard A. Jackson. A simplified model for the dynamics of a three-way catalytic converter. SAE International, March 2000.

[12] D. Koenig, B. Marx, and D. Jacquet. Unknown input observers for switched nonlinear discrete time descriptor systems. IEEE Transaction on Automatic Control, 53(01) :373-379, February 2008.

[13] I.D. Landau. System Identification and Control. Prentice Hall (Englewood Cliffs, N.J.), 1990.

[14] Vinicius F. Montagner, Valter J.S. Leite, and Pedro L.D. Peres. Discrete-time switched systems : Pole location and structural constrained control. IEEE Conference on Decision and Control, pages 6242 - 6247, December 2003.

[15] Clifford N. Montreuil, Scott C. Williams, and Andrew A. Adamczyk. Modeling current generation catalytic converters : Laboratory experiments and kinetic parameter optimization - steady state kinetics. SAE International, February 1992.

[16] K. N. Pattas, A. M. Stamatelos, P. K. Pistikopoulos, G. C. Koltsakis, P. A. Konstandinidis, E. Volpi, and E. Leveron. Transient modeling of 3-way catalytic converters. SAE International, March 1994.

[17] Dimitrios N. Tsinoglou, Grigorios C. Koltsakis, and James C. Peyton Jones. Oxygen storage modeling in three-way catalytic converters. Ind. Eng. Chem. Res., 41 :1152-1165, 2002. 